\title{
Effect of discriminative plant-sugar feeding on the survival and fecundity of Anopheles gambiae
}

\author{
Hortance Manda*1,2, Louis C Gouagna ${ }^{3}$, Woodbridge A Foster ${ }^{4}$, \\ Robert R Jackson ${ }^{1,5}$, John C Beier ${ }^{6}$, John I Githure ${ }^{1}$ and Ahmed Hassanali ${ }^{1}$
}

\begin{abstract}
Address: ${ }^{1}$ International Centre of Insect Physiology and Ecology (ICIPE), PO Box 30772, Nairobi, Kenya, ${ }^{2}$ Department of Biological Sciences, Kenyatta University, PO Box 43844, Nairobi, Kenya, ${ }^{3}$ Département Société et Santé - UR016, Institut de Recherche pour le Développement (IRD), PO Box 182, Ouagadougou 01, Burkina Faso, ${ }^{4}$ Department of Entomology, The Ohio State University, Columbus, Ohio, USA, ${ }^{5}$ School of Biological Sciences, University of Canterbury, Christchurch, New Zealand and ${ }^{6}$ Department of Epidemiology and Public Health, University of Miami, Miami, Florida, USA

Email: Hortance Manda* - hmanda@mbita.mimcom.net; Louis C Gouagna - Louis-Clement.Gouagna@ird.bf;

Woodbridge A Foster - foster.13@osu.edu; Robert R Jackson - rjackson@mbita.mimcom.net; John C Beier - jbeier@med.miami.edu; John I Githure - jgithure@icipe.org; Ahmed Hassanali - ahassanali@icipe.org

* Corresponding author
\end{abstract}

Published: 2I August 2007

Malaria Journal 2007, 6:113
Received: 20 March 2007

Accepted: 2I August 2007

This article is available from: http://www.malariajournal.com/content/6/1/1/3

(C) 2007 Manda et al; licensee BioMed Central Ltd.

This is an Open Access article distributed under the terms of the Creative Commons Attribution License (http://creativecommons.org/licenses/by/2.0), which permits unrestricted use, distribution, and reproduction in any medium, provided the original work is properly cited.

\begin{abstract}
Background: A previous study showed for Anopheles gambiae s.s. a gradation of feeding preference on common plant species growing in a malaria holoendemic area in western Kenya. The present follow-up study determines whether there is a relationship between the mosquito's preferences and its survival and fecundity.

Methods: Groups of mosquitoes were separately given ad libitum opportunity to feed on five of the more preferred plant species (Hamelia patens, Parthenium hysterophorus, Ricinus communis, Senna didymobotrya, and Tecoma stans) and one of the less preferred species (Lantana camara). The mosquitoes were monitored daily for survival. Sugar solution (glucose $6 \%$ ) and water were used as controls. In addition, the fecundity of mosquitoes on each plant after (i) only one blood meal (number of eggs oviposited), and (ii) after three consecutive blood meals (proportion of females ovipositing, number of eggs oviposited and hatchability of eggs), was determined. The composition and concentration of sugar in the fed-on parts of each plant species were determined using gas chromatography. Using SAS statistical package, tests for significant difference of the fitness values between mosquitoes exposed to different plant species were conducted.
\end{abstract}

Results and Conclusion: Anopheles gambiae that had fed on four of the five more preferred plant species ( $T$. stans, $S$. didymobotrya, $R$. communis and $H$. patens, but not $P$. hysterophorus) lived longer and laid more eggs after one blood meal, when compared with An. gambiae that had fed on the least preferred plant species $L$. camara. When given three consecutive blood-meals, the percentage of females that oviposited, but not the number of eggs laid, was significantly higher for mosquitoes that had previously fed on the four more preferred plant species. Total sugar concentration in the preferred plant parts was significantly correlated with survival and with the proportion of females that laid eggs. This effect was associated mainly with three sugar types, namely glucose, fructose, and gulose. Except for $P$. hysterophorus, the results suggest that feeding by mosquitoes on preferred plant species under natural conditions results in higher fitnessrelated benefits, and that the sugar content in preferred plant parts is largely responsible for these effects. 


\section{Background}

For most mosquito species, floral nectar and extra-floral plant fluids are the female's primary source of dietary sugar and the male's only source of nutrients $[1,2]$. Yet the influence of plant feeding on mosquito fitness remains poorly understood, and this may be a serious gap in the knowledge of factors that affect the biotic potential, population dynamics and habitat suitability of Anopheles gambiae s.s., the primary vector of Plasmodium falciparum in sub-Saharan Africa [3-5]. Laboratory studies suggest that sugar meals may have an important influence on the flight performance, survival, and fecundity of adult mosquitoes $[6,7]$. However, interpreting findings from laboratory studies on An. gambiae has not been straightforward because, although females live longer when sugar is available [8-11], their daily fecundity is lower [9], apparently because of delayed onset or completion of oviposition $[12,13]$.

Current knowledge of the effects of plant-mosquito interactions on fitness is fragmented, with respect to both experimental conditions and the component of fitness that is affected most. For instance, only two previous studies have focused on the survival of An. gambiae when feeding on plants $[14,15]$. However, the plants used were selected arbitrarily. One crucial question that has remained largely unaddressed, however, concerns the effect of sugar meals on mosquito survivorship and reproductive success in the presence versus the absence of preferred sugar sources. From an evolutionary standpoint, plants with high sugar content may confer correspondingly high survival reward and can be assumed to be more attractive to mosquitoes than plants with lower sugar content. In a recent study [16], feeding preferences of An. gambiae and the plant parts they preferred feeding on were ranked. This was done by giving the mosquitoes access to 13 of the dominant plant species growing in western Kenya. Testing was done in choice (i.e. with all the plant species present simultaneously) and in no-choice (i.e. with one plant species present at a time) situations. The present study proposes that An. gambiae's preference ranking of plants matches the relative fitness-related benefits the mosquito derives from feeding on the different plant species. Survival and fecundity are specifically considered here, these being widely recognized as especially relevant to fitness. In addition, to assess plant-related influences on the fitness of An. gambiae, the quality and quantity of sugar from the plants tested were measured and the association of these variables with mosquito survival and fecundity were examined. The initial hypothesis of this study was that An. gambiae has evolved an ability to identify and feed preferentially on plant species that have especially high sugar content, with these, in turn, being plants on which An. gambiae has higher survival and fecundity.

\section{Materials and methods \\ Study area}

The study was carried out on the shores of Lake Victoria at the Thomas Odhiambo Campus (TOC) of the International Centre of Insect Physiology and Ecology (ICIPE) in Mbita Point, a village of about 8,000 people (primarily fishermen and traditional farmers) in Suba District, western Kenya. This is a locality of holoendemic malaria with about five infective bites per person per year $[17,18]$. Although Anopheles arabiensis and Anopheles funestus are also significant vectors of $P$. falciparum in Mbita Point, the primary vector is An. gambiae s.s. [17,18]. Plasmodium falciparum malaria is the leading cause of morbidity for residents in the area, accounting for $50-60 \%$ of all clinically diagnosed illness at the local health centre [19]. Mean minimum and maximum daily temperatures are $17^{\circ} \mathrm{C}$ and $34^{\circ} \mathrm{C}$, respectively. Annual rainfall is $700-1200 \mathrm{~mm}$, coming primarily during two rainy seasons, March to May and October to November. Permanent and semi-permanent larval habitats for An. gambiae are widespread during the dry seasons. Vegetation, which includes a wide variety of indigenous and introduced plants, remains verdant all year. Various shrubs and herbaceous plants are usually found around larval habitats, human habitations, and roadsides, representing potential sugar sources for local mosquitoes.

\section{Mosquitoes}

Mosquitoes used in this study were obtained from a colony reared at ambient temperature and humidity, established in 2001 from blood-fed and gravid An. gambiae s.s. caught in Mbita Point. Adults were kept in standard $30 \times$ $30 \times 30 \mathrm{~cm}$ mesh-covered cages at the ICIPE-TOC insectary and offered a $6 \%$ glucose solution ad libitum. Females were also allowed to feed on a human volunteer arm for 15 min on three consecutive nights per gonotrophic cycle. Approval for feeding the mosquitoes on human subjects was obtained from the Kenya National Ethical Review Board (protocol number KEMRI/RES/7/3/1). Fully engorged females were then allowed to lay eggs in oviposition cups ( $4 \mathrm{~cm}$ diameter, $2 \mathrm{~cm}$ depth) placed inside the cages. Eggs were collected the following day and dispensed into plastic trays $(25 \mathrm{~cm}$ long $\times 20 \mathrm{~cm}$ wide $\times 14$ $\mathrm{cm}$ high) filled to a depth of $8 \mathrm{~cm}$ with filtered water collected from Lake Victoria. Upon hatching, larvae were reared in these pans at densities of 100-150 per tray and fed fish food (Tetramin ${ }^{\circledR}$ ) three times per day. For experiments, pupae were transferred to standard cages and the emerging adults were denied access to blood or sugar prior to experiments, which started on the second day after emergence. 


\section{Assessment of plant-feeding success and mosquito preference for different plant species and plant parts} A previous study [16] determined An. gambiae's feeding responses to 13 perennial plant species: Cassia hirsuta, Datura stramonium, Flaveria trinervia, Hamelia patens, Ipomea hildebrandtie, Lantana camara, Parthenium hysterophorus, Psiada punctulata, Ricinus communis, Senna bicapsularis, Senna didymobotrya, Tecoma stans and Tithonia diversifolia. These plants were selected on the basis of their local availability in the vicinity of human dwellings and larval habitats of An. gambiae within a radius of $30 \mathrm{~km}$ around Mbita Point in western Kenya. Groups of 100 or 200 mosquitoes were released into cages and left overnight either with cuttings (branches with inflorescences) of one plant type at a time (no-choice assay) or with cuttings of all 13 plants simultaneously (choice assay), respectively. In the choice assay, direct observations of the numbers and percentages of mosquitoes perching or feeding on each plant species and the plant parts were recorded over four one-hour periods each night. For both types of assay, mosquitoes were recaptured and the percentage that had fed on plants was assessed by testing them individually for the presence of fructose. To confirm the plants and plant parts mosquitoes had fed on during the choice-assays, gas chromatography (GC) profiles of a sub-sample of mosquito homogenates were compared with GC profiles of extracts from relevant parts of each plant. It was found that $A n$. gambiae is differentially responsive to this range of plants, regardless of whether the plants were presented singly or mixed together. It was also found that significantly more females than males fed on the plants. A mean of $72 \%$ of the mosquitoes were observed feeding and 56\% of all mosquitoes recaptured were positive for fructose per trial in the choice assay. Means of $60 \%, 4 \%$ and $8 \%$ were observed feeding on flowers, leaves and stems respectively, in the choice assay. For most plant species (ten of 13), GC profiles also indicated that An. gambiae obtained sugars primarily from flowers. The exceptions were $P$. hysterophorus L., L. camara L. and R. communis L., as An. gambiae fed from leaves and stems more often than from flowers of these three species.

\section{Plants}

Of the 13 plant species used in the study of An. gambiae's plant discrimination behaviour [16], six were selected for the present study (Table 1 and Figure 1). In that study, mosquitoes ranked four of these highest (Parthenium hysterophorus L., Tecoma stans L., Ricinus communis L., Senna didymobotrya $\mathrm{F}$.) in both choice and no-choice testing. One (Hamelia patens J.), although ranked lower by mosquitoes in no-choice assay, was among the more preferred plant species in the choice assay. The other plant (Lantana camara L.) was a representative less-preferred species. When needed, cuttings (branches with inflorescences) were collected from the field and taken to the laboratory for testing with mosquitoes, care being taken not to damage the plants during transportation. All plants were cleared of potential predators (ants, spiders and other) before testing began.

\section{Survival assay}

Batches of newly emerged (1-day old) mosquitoes, each consisting of 25 males and 25 females, were put in standard $(30 \times 30 \times 30 \mathrm{~cm})$ cages and placed in a screen-walled hazard-proof greenhouse $(11.5 \times 7.1 \mathrm{~m})$. Randomly constituted groups of mosquitoes were exposed to each of the six plants species. In control groups, other batches of mosquitoes were allowed continuous access either to a $6 \%$ (wt:vol) glucose solution in filter-paper wicks (positive control) or water pads only (negative control). There was also a second negative control (a group deprived of sugar and of water). For each treatment group, cuttings with flowers from each of the six plant species were used, each being held in a $250 \mathrm{ml}$ Erlenmeyer flask filled with fresh Lake Victoria water, the top being plugged with cotton wool and sealed with Parafilm ${ }^{\circledast}$ (Pechiney Plastic Packaging, Menasha, WI, USA) to block the mosquito's access to the water. The experimental setup was exposed to fluctuating ambient temperature range of $18-31^{\circ} \mathrm{C}$. Direct sunlight, hence extremes of temperature, was prevented by a layer of reed mats suspended beneath the glass roof of the experimental arena. Mosquitoes in each cage had access to one of the six plant species and to cotton pads wetted with distilled water. Plant material, glucose solution, and water pads were changed every two days. The survival of both female and male mosquitoes kept on different nutritional regimes was monitored until all the mosquitoes had died. Dead mosquitoes were removed and counted daily from each cage. All tests were replicated six times between April and December 2004.

\section{Fecundity assay}

Two experiments were conducted for each plant species: a one-blood-meal (1-bm) experiment, replicated four times, and a three-blood-meal (3-bm) experiment, replicated seven times. For both, batches of 100 An. gambiae (50 females and 50 males) that emerged the previous night were released into each of eight standard cages. The rationale for putting males and females in each cage was to increase the chance that the females would be inseminated. In six cages, the mosquitoes were allowed access to each of the six plant species (one plant species per cage). In other two cages, mosquitoes were provided continuous access either to $6 \%$ (wt:vol) glucose solution in filterpaper wicks (positive control) or distilled water in cotton pads (negative control). In the 1-bm experiment, which began on the evening of the third day following exposure to plants, sugar or water, batches of female mosquitoes were allowed to feed on blood from a human arm (the same volunteer for each replicate) for $15 \mathrm{~min}$. In the 3-bm 


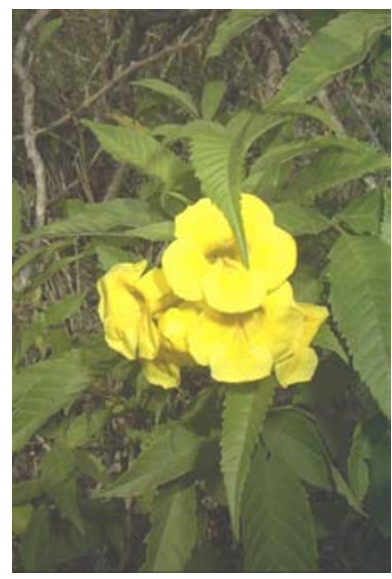

Tecoma stans L.

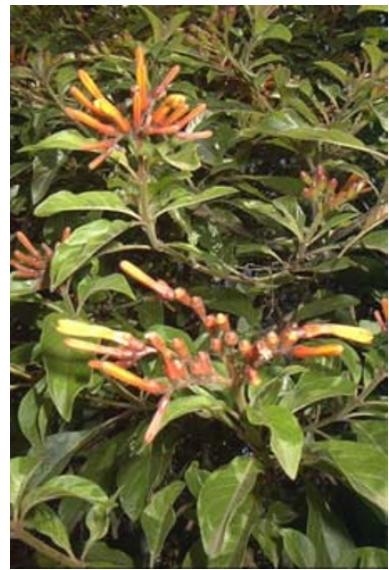

Hamelia patens Jacq

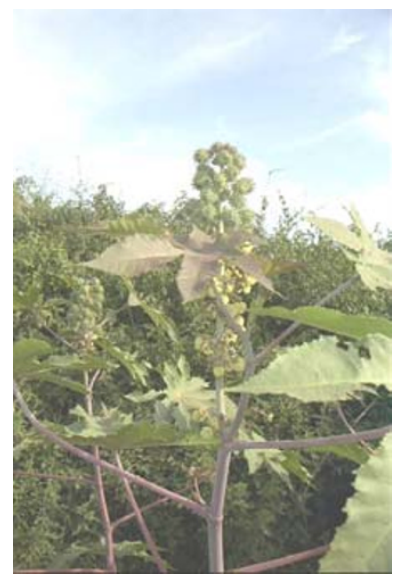

Ricinus communis $\mathbf{L}$.

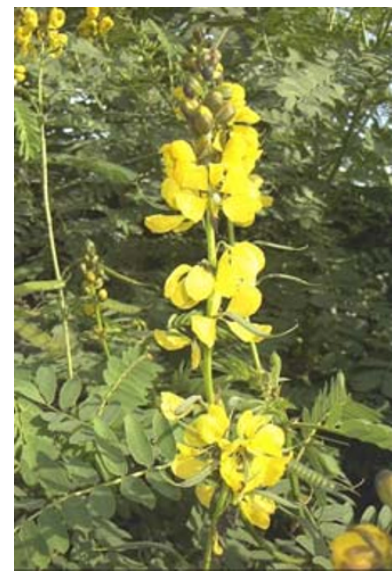

Senna didymobotrya Fresen

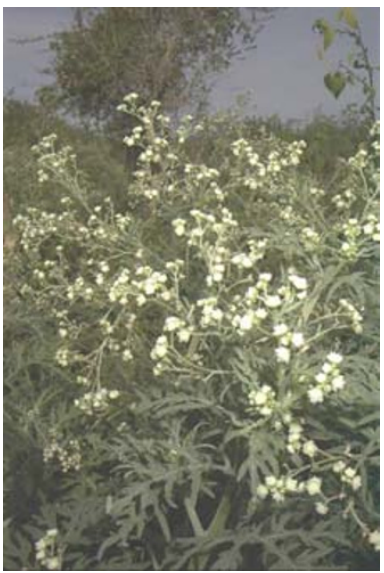

Parthenium hysterophorus L.

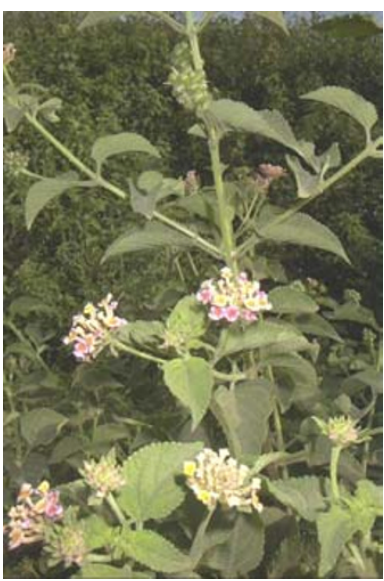

Lantana camara $\mathbf{L}$.

\section{Figure I}

Plant species used in survival and fecundity study of An. gambiae.

experiment, female mosquitoes from each group were offered three successive blood meals (for $15 \mathrm{~min}$ each time) starting on the third day (i.e., blood meal offered on third, fourth and fifth evening). The 3-bm experiment was included because multiple blood meals have been shown previously to make vitellogenesis and egg maturation more likely to occur in Anopheles females [20]. Mosquitoes that failed to feed on blood were discarded after the first blood-feeding period. Immediately after blood feeding, and for the entire period of the assay, blood-fed mosquitoes were held in cages under their respective nutritional regimes. Based on previous experience, it was predicted that at least $90 \%$ of the mosquitoes surviving until the third evening after the start of the experiment would have fed at least once on the plant.
On the third evening following the one blood meal for the 1-bm experiment, or on the second evening following the third blood meal for the 3-bm experiment, gravid and hypergravid (delayed onset of oviposition) female mosquitoes were placed individually in smaller $(15 \times 15 \times 15$ $\mathrm{cm}$ ) holding cages and given continual access to their respective food regimes. Plant cuttings were put in a 100 $\mathrm{ml}$ Erlenmeyer flask, filled with fresh lake water (access to the water in the flask prevented as indicated above). Food regimes were refreshed every 2 days.

In both the fecundity experiments, oviposition was allowed for 7 consecutive days by supplying individual mosquitoes with one plastic oviposition cup ( $4 \mathrm{~cm}$ diameter, $2 \mathrm{~cm}$ depth) containing $15 \mathrm{ml}$ of distilled water and an inserted filter-paper cone over the top. During the 7day period, although plants inside the cages were also 
Table I: List and common names of plant species used in survival and fecundity study of An. gambiae

\begin{tabular}{|c|c|c|}
\hline Family & Species & Common name \\
\hline Rubiaceae & Hamelia patens Jacq & Firebush \\
\hline Verbenaceae & Lantana camara L. & Wild sage \\
\hline Asteraceae & $\begin{array}{l}\text { Parthenium } \\
\text { hysterophorus L. }\end{array}$ & Wild quinine \\
\hline Euphorbiaceae & Ricinus communis $\mathrm{L}$. & Castorbean \\
\hline Leguminosae & $\begin{array}{l}\text { Senna didymobotrya } \\
\text { Fresen }\end{array}$ & African senna \\
\hline Bignoniaceae & Tecoma stans L. & Yellow bells \\
\hline
\end{tabular}

checked for the presence of eggs, the mosquitoes always laid their eggs on the wet filter paper. Starting at $09.00 \mathrm{~h}$ each morning, each cup was changed and the number of eggs laid by each mosquito was counted under a dissection microscope. In the 3-bm experiment, dead mosquitoes found during the oviposition period were individually dissected, their ovaries were examined for the presence of retained eggs and the numbers of eggs were recorded. After the oviposition period, for each group the numbers of eggs retained were also determined by dissecting the remaining mosquitoes. The mean number of eggs produced by mosquitoes in each group was obtained by counting the number of eggs oviposited plus the number of eggs retained.

To determine egg viability, eggs laid by mosquitoes that have been exposed to the same nutritional regime were pooled and dispensed into plastic trays $(25 \mathrm{~cm}$ long $\times 20$ $\mathrm{cm}$ wide $\times 14 \mathrm{~cm}$ high) filled with filtered Lake Victoria water to a depth of $8 \mathrm{~cm}$. First instar larvae were counted upon hatching.

\section{Extraction and quantification of sugars present in each plant}

Using gas chromatography (GC), the sugar composition and the concentration of each sugar component in floral and extrafloral parts of each plant were determined. For each plant tested, parts (flowers and leaves) were extracted for analyses. Flowers included nectar and floral tissue. In the case of $R$. communis, stems (= petioles) were also included for analysis because mosquitoes were observed feeding from extrafloral nectaries on the stems of this plant species [16]. Using small cryo-preservation vials containing $200 \mu \mathrm{l}$ of a 50\% EDTA solution, approximately the same mass of flowers or leaves (or stems for R. communis) were incubated in the dark for $2 \mathrm{~h}$, after which the plant material was removed and extracts remaining in the vials dried under a flow of pure nitrogen [21] and then analysed as described below.

\section{Sugar standards}

Analytical grade sugars used as standards were obtained from Sigma-Aldrich Co. (Poole, Dorset, UK). Nine standards were prepared for derivatization and GC: $\alpha$-D-glucose, $\mathrm{D}(+)$ raffinose, $\mathrm{D}(+)$ galactose, $\mathrm{D}(+)$ mannose, $\beta$-Dfructose, sucrose, D-gulose, D-altrose, and D-allose. For checking the analytical procedure, $\alpha$-lactose was also included.

\section{Trimethylsilylation of standards and samples}

Sugar analysis by GC requires initial silylation of the highly polar carboxyl and hydroxyl groups. Using previously described analytical procedures [21], sugar standards were trimethylsilylated in a clean 2-ml reacti-vial by dissolving $1 \mathrm{mg}$ of each in $100 \mu \mathrm{l}$ of dry pyridine. An equal volume of N-methyl-N-trimethylsilyltrifluoroacetanamide (MSTFA) was then added. The mixture was placed in an oven set at $60^{\circ} \mathrm{C}$ and left for $60 \mathrm{~min}$, after which the sample was removed and stored at room temperature until analysis. Plant extracts were similarly processed and derivitized.

\section{Gas chromatographic analysis of sugars}

These were performed on a Hewlett Packard (HP) (Walbronn Division B4, W-Germany) 5890 series II gas chromatograph, equipped with a split-less injector system, a $50 \mathrm{~m} \times 0.2 \mathrm{~mm}$ (i.d.) crossed-linked methylsilicone $(0.33$ $\mu \mathrm{m}$ film thickness) capillary column and FID-coupled to an HP 3393 A Series II integrator. The carrier gas was nitrogen, with flow set at $0.8 \mathrm{ml} / \mathrm{min}$. The initial temperature $\left(100^{\circ} \mathrm{C}\right)$ was increased at $30^{\circ} \mathrm{C} / \mathrm{min}$ up to $170^{\circ} \mathrm{C}$ and then at $2^{\circ} \mathrm{C} / \mathrm{min}$ to $210^{\circ} \mathrm{C}$, followed by $50^{\circ} \mathrm{C} / \mathrm{min}$ to a final isothermal temperature of $280^{\circ} \mathrm{C}$ that was maintained for $30 \mathrm{~min}$.

The derivatized sugar standards were diluted by a factor of 40 with dichloromethane (DCM 99.9+\%, PRA grade). Three parts of the derivatized plant extract were diluted with one part of the same solvent, and $1 \mu \mathrm{L}$ of each sample was injected into the gas chromatograph (using DCM to clean syringes between samples). Plant-derived sugars were identified by comparing retention times of sugar standards with those present in the plant extracts. The amount of each sugar in the plant samples was determined by accounting for the dilution factors and using the following formula:

$\mathrm{Xi}=\left(\mathrm{P}_{\mathrm{i}} / \mathrm{P}_{\mathrm{s}}\right)\left(\mathrm{X}_{\mathrm{s}}\right)$

where $P_{i}$ and $P_{s}$ are peak areas of sample and standard respectively, and $\mathrm{X}_{\mathrm{s}}$ the quantity of sugar standard injected. 


\section{Statistical analyses}

Survival analysis techniques (PROC LIFETEST), including a log-rank test, were used to compare survival curves and test whether the survival rate differed between different nutritional regimes and between the sexes. Effects of feeding treatment on survivorship were estimated using analysis of variance (ANOVA) on transformed $\left(\log _{10}\right)$ data. For all measurements, means \pm standard errors are given. Mean survival times were compared between groups using a Student-Newman-Keuls (SNK) test.

Data from the fecundity assay were either 1) $\log _{10}$-transformed for number of eggs produced, retained and laid per female in each nutritional regime or 2) arcsin-transformed for the percentages of mosquitoes that oviposited and for eggs that hatched. With ANOVA, the transformed data were analysed for effects of the nutritional regime, with means for these variables being compared separately using the SNK test.

The survival time and fecundity indices in mosquitoes exposed to different nutritional regimes were expressed relative to the positive control (glucose) as follows: value $=($ control-treatment $) /$ control. Spearman correlation was used to detect potential linear relationships between sugar content of the plant parts preferred by the mosquitoes (flowers for T. stans, S. didymobotrya and H. patens, stems for R. communis, and leaves for L. camara and P. hysterophorus) [16] and mosquito median survival time and fecundity. Sugar concentration in flowers and leaves were compared using $t$-test. All mosquitoes that escaped or were inadvertently killed while handling were excluded from data analysis. For all analysis, the significance level was set at $\mathrm{P} \leq 0.05$. Analyses were carried out with Excel $2000^{\circledast}$ and SAS version 8.2 for Windows ${ }^{\circledast}$.

\section{Results \\ How different plant species affected An. gambiae's survival}

Mean survival times of mosquitoes varied significantly among the nutritional regimes $(\mathrm{F}=202.81, \mathrm{df}=8, \mathrm{P}<$ $0.001)$. Mosquitoes that were given access to glucose solution (6\%) survived significantly longer than mosquitoes from any other group. Survival time was shortest when mosquitoes were exposed to water alone (negative control) and to no water, glucose or plants (second negative control). Survival time on P. hysterophorus was comparable to survival times on the negative controls (Table 2). Survival time of mosquitoes on L. camara, the least preferred of the six plants investigated, was significantly higher than on the negative controls ( $\mathrm{P}<0.001$ for each) or on $P$. hysterophorus $(\mathrm{P}<0.001)$, and comparable to that of mosquitoes on $H$. patens $(P=0.2)$. However, survival time on $L$. camara was significantly lower than on the other plants or on the control (glucose) $(\mathrm{P}<0.001$ for each) (Table 2$)$.

Overall, the ranking (from highest to lowest) of mean survival times of mosquitoes on the various plant species was as follows (Table 2): T. stans, S. didymobotrya, R. communis, H. patens, L. camara and P. hysterophorus.

Relative to the glucose solution, $T$. stans, $S$. didymobotrya and $R$. communis reduced survival of mosquitoes by $18 \%$, $30 \%$ and $32 \%$, respectively. H. patens (50\%) was comparable to $L$. camara (58\%), whereas P. hysterophorus and negative controls caused the highest reduction in survival $(>70 \%)$.

The proportion of mosquitoes surviving over time was influenced by feeding regime $\left(\chi^{2}=1633, \mathrm{df}=8, \mathrm{P}<0.001\right)$ (Figure 2). There were especially rapid declines in the proportions of surviving mosquitoes in the negative controls

Table 2: Survival times in days of An. gambiae exposed to different nutritional regimes

\begin{tabular}{|c|c|c|c|c|c|c|c|}
\hline Nutritional regime & $N$ & Median & Mean & $\pm \mathrm{SE}$ & Range & $\begin{array}{l}\text { Survival } \\
\text { index }\end{array}$ & $\mathrm{P}$ \\
\hline Glucose (6\%) & 300 & 16.0 & $17 .\left.\right|^{a}$ & 0.4 & $2.0-35.0$ & $0.00 *$ & NA \\
\hline T. stans & 294 & 12.0 & $13.4^{\mathrm{b}}$ & 0.5 & $2.0-55.0$ & $0.18^{a}$ & 0.06 \\
\hline S. didymobotrya & 278 & 11.0 & $11.6 \mathrm{c}$ & 0.3 & $2.0-34.0$ & $0.30^{\mathrm{a}}$ & 0.03 \\
\hline R. communis & 293 & 10.0 & $11.4^{c}$ & 0.4 & $2.0-37.0$ & $0.32^{\mathrm{a}}$ & 0.01 \\
\hline H. patens & 288 & 7.0 & $7.7^{d}$ & 0.3 & $2.0-32.0$ & $0.50^{\mathrm{b}}$ & 0.001 \\
\hline L. camara & 286 & 6.0 & $7.2^{\mathrm{d}}$ & 0.2 & $2.0-26.0$ & $0.58^{b}$ & $<0.001$ \\
\hline P. hysterophorus & 290 & 4.0 & $4.7 e$ & 0.2 & $2.0-26.0$ & $0.72^{c}$ & $<0.001$ \\
\hline Water (-ve control) & 297 & 3.0 & $3.8 \mathrm{e}$ & 0.1 & $2.0-12.0$ & $0.77^{c}$ & $<0.001$ \\
\hline None (2nd -ve control) & 296 & 3.0 & $3.0 \mathrm{e}$ & 0.0 & $2.0-6.0$ & $0.80^{c}$ & $<0.001$ \\
\hline
\end{tabular}

$\mathrm{N}$ is total number of mosquitoes tested

SE is Standard error of mean

Survival index: (C-T)/C [(glucose control - treatment)/glucose control] expresses the effect of each treatment on the mean survival time of mosquitoes relative to the positive control (glucose)

Means and survival index with different letter superscripts in the same column are significantly different (SNK test at $\alpha=0.05)$

* Reference group 
Table 3: Sex differences in survival times and curves of An. gambiae, stratified by nutritional regime (log-rank test)

\begin{tabular}{|c|c|c|c|c|}
\hline Nutritional regime & Males $(\mathrm{N})$ Means \pm SE (in days) & Females $(\mathrm{N})$ Means \pm SE (in days) & $\chi^{2 *}$ & $P$ \\
\hline Glucose $(6 \%)$ & (148) $17.3 \pm 0.6$ & (I5I) $17.2 \pm 0.6$ & 0.004 & 0.94 \\
\hline T. stans & (I45) $14.2 \pm 0.8$ & (154) $13.2 \pm 0.6$ & 0.89 & 0.34 \\
\hline S. didymobotrya & $(131) 11.9 \pm 0.5$ & (142) $11.4 \pm 0.5$ & 0.01 & 0.88 \\
\hline R. communis & (143) $10.9 \pm 0.5$ & (142) $12.6 \pm 0.6$ & 3.07 & 0.07 \\
\hline H. patens & $(136) 8.1 \pm 0.4$ & (I50) $7.4 \pm 0.4$ & 0.88 & 0.34 \\
\hline L. camara & (149) $7.6 \pm 0.3$ & (I45) $6.7 \pm 0.3$ & 2.93 & 0.08 \\
\hline P. hysterophorus & (138) $4.7 \pm 0.3$ & (I4I) $4.7 \pm 0.3$ & 0.002 & 0.96 \\
\hline Water (-ve control) & (148) $3.8 \pm 0.1$ & (I49) $3.8 \pm 0.1$ & 0.01 & 0.90 \\
\hline None ( $2^{\text {nd }}$-ve control) & $2.9 \pm 0.07$ & (I43) $3.1 \pm 0.07$ & 2.58 & 0.10 \\
\hline
\end{tabular}

* Test statistic for log-rank analysis: survival distribution between male and female mosquitoes in each respective nutritional regime

$\mathrm{N}$ is number of mosquitoes tested

$\mathrm{SE}$ is standard error of mean.

and in the $P$. hysterophorus groups, with numbers dropping dramatically during the first 5 days. Only $10 \%$ of the mosquitoes exposed to $P$. hysterophorus survived longer than 7 days. Survival rate also declined rapidly when mosquitoes were exposed to L. camara, with $80 \%$ being dead by day 10. Male and female mosquitoes that were exposed to $6 \%$ glucose solution or to T. stans, $R$. communis or S. didymobotrya had consistently higher survival rates than the other groups, and mortality rate was distributed more uniformly throughout the experimental period (Figure 2). There were no significant differences between the survival rates over time of males and females exposed to different plants (pooled replicates and pooled plants) $\left(\chi^{2}=0.28, \mathrm{df}\right.$ $=1, P=0.63)$. Nor were there significant sex differences in mean survival times and survival curves found for individual plant species ( $\mathrm{P}$ values, 0.34-0.94, Table 3).

\section{How different plant species affected An. gambiae's fecundity}

When mosquitoes were offered only one blood meal, the number of eggs laid per mosquito varied significantly among groups exposed to the different plant species $(\mathrm{F}=$ $2.82, \mathrm{df}=7, \mathrm{P}=0.01)$. The numbers of eggs laid by mosquitoes that had been exposed to T. stans, R. communis, $S$. didymobotrya or $H$. patens were comparable to the number laid by mosquitoes that had fed on glucose. Mosquitoes from the P. hysterophorus and the L. camara groups laid significantly fewer eggs than mosquitoes from other groups,

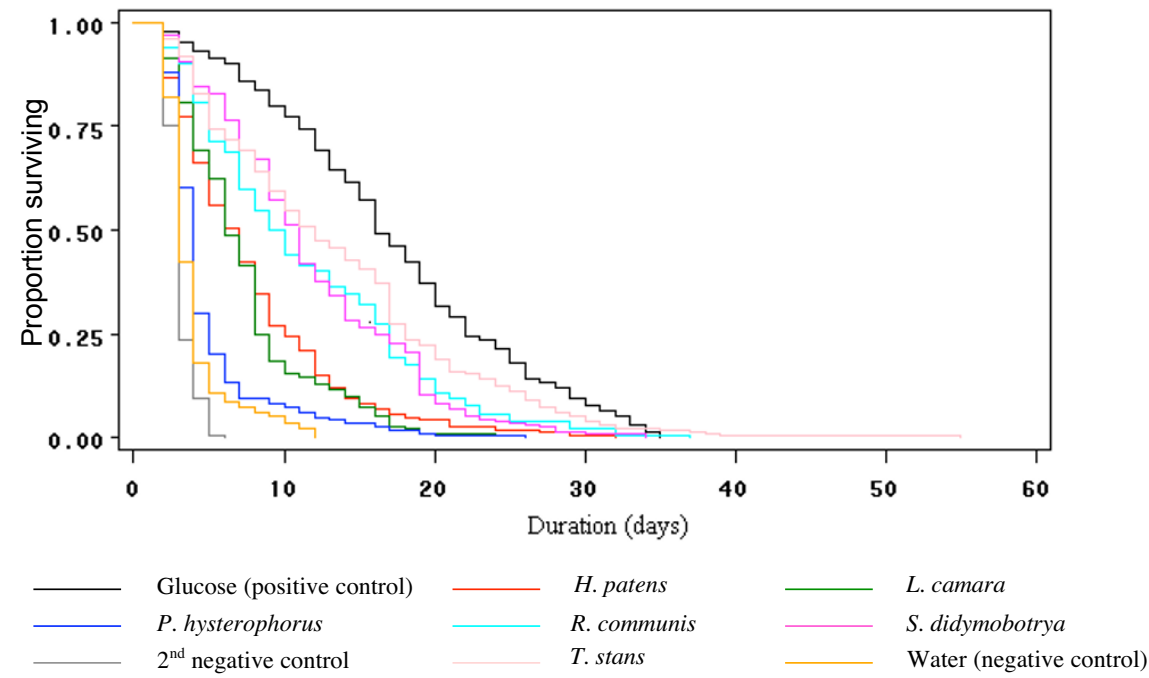

Figure 2

Survival curves of An. gambiae (pooled males and females) exposed to different nutritional regimes.

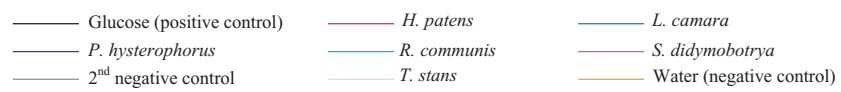


these being comparable to the number of eggs laid by mosquitoes from the negative control (Table 4).

For mosquitoes offered three consecutive blood meals, although there was no significant variation in the proportion of mosquitoes that produced eggs per group $(\mathrm{F}=$ 1.33 , $\mathrm{df}=7, \mathrm{P}=0.25)$, there was significant variation in the proportions of mosquitoes that oviposited $(\mathrm{F}=3.38$, $\mathrm{df}=7, \mathrm{P}=0.006)$ and the proportions of mosquitoes that retained eggs $(\mathrm{F}=2.90, \mathrm{df}=7, \mathrm{P}=0.014)$. Significantly fewer mosquitoes maintained on $P$. hysterophorus, $L$. camara or water (negative control) oviposited any eggs at all (Table 5). These three nutritional regimes reduced the percentage of mosquitoes ovipositing by more than $40 \%$ relative to the positive control (glucose solution). In the $T$. stans, $S$. didymobotrya or $R$. communis groups, proportions of mosquitoes ovipositing were comparable to the positive control, whereas that of mosquitoes from the H. patens group was intermediate (Table 5). However, there was no notable effect of diet on the numbers of eggs produced (Table 5). The numbers of eggs retained $(\mathrm{F}=1.48, \mathrm{df}=6$, $\mathrm{P}=0.17)$ and laid $(\mathrm{F}=1.29, \mathrm{df}=6, \mathrm{P}=0.29)$ per female were similar across plant species and controls (Table 5). Egg hatchability did not vary significantly among different nutritional groups $(\mathrm{F}=1.68, \mathrm{df}=7, \mathrm{P}=0.14)$ (Table 5), suggesting no effect of sugar source on egg viability.

\section{Sugar composition and concentration in plant extracts and correlation with mosquito survival and fecundity}

Sugar composition and concentration varied among the plant species (Table 6). Of the sugars tested, $\alpha$-D-glucose, $\beta$-D-fructose, sucrose, $\mathrm{D}(+)$ mannose, and D-gulose were dominant in all species. Across plant species, sugar tended
Table 4: Fecundity of An. gambiae offered one blood meal and exposed to each nutritional regime

\begin{tabular}{lcc}
\hline Nutritional Regime & $\mathrm{N}$ & $\begin{array}{c}\text { Eggs laid Mean } \pm \text { SE } \\
\text { (female laying) }\end{array}$ \\
\hline Glucose (6\%) & 44 & $35.7 \pm 2.1^{\mathrm{a}}$ \\
T. stans & 40 & $34.8 \pm 2.0^{\mathrm{a}}$ \\
S. didymobotrya & 46 & $33.1 \pm 1.9^{\mathrm{a}}$ \\
R. communis & 39 & $33.0 \pm 2.3^{\mathrm{a}}$ \\
H. patens & 48 & $39.1 \pm 2.6^{\mathrm{a}}$ \\
L. camara & 46 & $21.2 \pm 2.5^{\mathrm{b}}$ \\
P. hysterophorus & 38 & $15.1 \pm 2.0^{\mathrm{b}}$ \\
Water & 16 & $15.5 \pm 3.2^{\mathrm{b}}$ \\
\hline
\end{tabular}

$\mathrm{N}$ is number of mosquitoes that oviposited

$\mathrm{SE}$ is standard error of mean

Any two means sharing a letter superscript in common are not significantly different (SNK test at $\alpha=0.05$ )

to be more concentrated in flowers than in leaves $(t=$ 2.48, $P=0.01$ after pooling data across plant species) (Table 6$)$. The highest sugar diversity $(78 \%$ of sugars tested) and the highest total concentration of sugar (506 $\mu \mathrm{g} / \mathrm{mg}$ of dry extract) were found in the flowers of $T$. stans. The lowest sugar diversity ( $22 \%$ of sugars tested) and the lowest total concentration ( $2 \mu \mathrm{g} / \mathrm{mg}$ of dry extract) were found in the leaves of $P$. hysterophorus, the flowers of this plant having no identifiable sugars at all.

There was a significant positive correlation between the total amount of sugar present in the preferred part of each plant species [16] and median survival time of mosquitoes exposed to the plants $(\mathrm{r}=1.00, \mathrm{P}<0.001)$, and

Table 5: Fecundity of An. gambiae offered three blood meals and exposed to each nutritional regime

\begin{tabular}{|c|c|c|c|c|c|c|c|c|}
\hline $\begin{array}{l}\text { Nutritional } \\
\text { regime }\end{array}$ & $N$ & $\begin{array}{l}\text { Number of } \\
\text { eggs } \\
\text { produced } \\
\text { Mean } \pm \text { SE }\end{array}$ & $\begin{array}{l}\text { Number of } \\
\text { eggs retained } \\
\text { Mean } \pm \text { SE } \\
\text { (per female } \\
\text { retaining) }\end{array}$ & $\begin{array}{c}\text { \% Mosquitoes } \\
\text { ovipositing } \\
\text { Mean } \pm \text { SE }\end{array}$ & $\begin{array}{l}\text { Oviposition } \\
\text { index }\end{array}$ & $P$ & $\begin{array}{l}\text { Number of } \\
\text { eggs laid } \\
\text { Mean } \pm \text { SE } \\
\text { (per female } \\
\text { laying) }\end{array}$ & $\begin{array}{c}\% \text { Eggs } \\
\text { hatched Mean } \\
\pm \text { SE }\end{array}$ \\
\hline Glucose (6\%) & 117 & $76.5 \pm 3.5^{\mathrm{ab}}$ & $60.4 \pm 5.2^{\mathrm{a}}$ & $71.2 \pm 6.7^{\mathrm{a}}$ & $0^{*}$ & NA & $77.0 \pm 4.6^{a}$ & $67.4 \pm 1.2^{\mathrm{a}}$ \\
\hline T. stans & 115 & $63.4 \pm 3.1 \mathrm{ab}$ & $50.1 \pm 4.0^{a}$ & $69.2 \pm 6.7^{a}$ & $0.02^{\mathrm{a}}$ & 0.85 & $67.4 \pm 3.9 a$ & $69.0 \pm 6.8^{a}$ \\
\hline $\begin{array}{l}\text { S. } \\
\text { didymobotrya }\end{array}$ & 115 & $70.1 \pm 3.2^{\mathrm{ab}}$ & $63.1 \pm 5.0^{a}$ & $64.5 \pm 6.8^{\mathrm{ab}}$ & $0.09^{a}$ & 0.78 & $68.0 \pm 4.2^{\mathrm{a}}$ & $61.9 \pm 3.3^{a}$ \\
\hline R. communis & 90 & $78.2 \pm 3.7^{a}$ & $67.4 \pm 5.5^{\mathrm{a}}$ & $60.5 \pm 7.3^{\mathrm{ab}}$ & $0.15^{\mathrm{a}}$ & 0.75 & $79.3 \pm 4.7 \mathrm{a}$ & $58.3 \pm 7.7^{a}$ \\
\hline H. patens & 95 & $66.0 \pm 3.5^{\mathrm{ab}}$ & $60.5 \pm 4.5^{\mathrm{a}}$ & $46.8 \pm 8.0^{b c}$ & $0.34^{b}$ & 0.46 & $67.7 \pm 5.8^{a}$ & $67.3 \pm 9.1 \mathrm{a}$ \\
\hline L. camara & 82 & $70.6 \pm 3.8^{a b}$ & $65.0 \pm 5.8^{a}$ & $40.2 \pm 7.6^{c}$ & $0.43^{b c}$ & 0.03 & $75.6 \pm 5.1^{a}$ & $67.8 \pm 4.1^{a}$ \\
\hline $\begin{array}{l}\text { P. } \\
\text { hysterophorus }\end{array}$ & 80 & $60.4 \pm 3.6^{b}$ & $53.7 \pm 6.1^{\mathrm{a}}$ & $39.1 \pm 10.7 c$ & $0.45 \mathrm{bc}$ & 0.02 & $57.8 \pm 4.1^{\mathrm{a}}$ & $34.4 \pm 4.9 \mathrm{a}$ \\
\hline Water & 69 & $66.7 \pm 3.9 \mathrm{ab}$ & $67.2 \pm 4.8^{\mathrm{a}}$ & $27.5 \pm 6.8^{c}$ & $0.60^{c}$ & 0.007 & $58.5 \pm 6.1^{a}$ & $61.6 \pm 17.4^{a}$ \\
\hline
\end{tabular}

$\mathrm{N}$ is number of mosquitoes tested; $\mathrm{SE}$ is standard error of mean

Oviposition index: (C-T)/C [(glucose control - treatment)/glucose control] expresses the effect of each treatment on the percentage of mosquitoes ovipositing, relative to the positive control (glucose)

Any two means in the same column sharing a letter superscript in common are not significantly different (SNK test at $\alpha=0.05$ )

* Reference group 
Table 6: Sugars present in each plant species and quantity in I mg dried extract of plant parts

\begin{tabular}{|c|c|c|c|c|c|c|c|c|c|c|c|}
\hline Plants & Plant part & $\begin{array}{c}\alpha \text {-D- } \\
\text { Glucose } \\
(\mu g)\end{array}$ & $\begin{array}{c}\beta-D- \\
\text { Fructose } \\
(\mu g)\end{array}$ & $\begin{array}{c}\text { Sucrose } \\
(\mu g)\end{array}$ & $\begin{array}{c}\text { D- } \\
\text { Mannose } \\
(\mu g)\end{array}$ & $\begin{array}{c}\text { D-Gulose } \\
(\mu \mathrm{g})\end{array}$ & $\begin{array}{c}\text { D- } \\
\text { Galactose } \\
(\mu \mathrm{g})\end{array}$ & $\begin{array}{c}\text { D- } \\
\text { Raffinose } \\
(\mu g)\end{array}$ & $\begin{array}{c}\text { D- } \\
\text { Altrose } \\
(\mu \mathrm{g})\end{array}$ & $\begin{array}{c}\text { D-Allose } \\
(\mu g)\end{array}$ & $\begin{array}{l}\text { Total } \\
(\mu g)\end{array}$ \\
\hline \multirow[t]{2}{*}{ H. patens } & Flower & 5.1 & 0 & 12.8 & 3.0 & 0 & 0 & 0 & 0 & 0 & 20.9 \\
\hline & Leaf & 0 & 0 & 0 & 0 & 0 & 0 & 0 & 0 & 0 & 0 \\
\hline \multirow[t]{2}{*}{ L. camara } & Flower & 43.8 & 30.6 & 2.4 & 8.6 & 134.6 & 0 & 0 & 0 & 0 & 220 \\
\hline & Leaf & 4.6 & 0 & 0 & 0 & 0 & 0 & 0 & 0 & 0 & 4.6 \\
\hline \multirow{3}{*}{$\begin{array}{l}R . \\
\text { communis }\end{array}$} & Flower & 23.3 & 0 & 0 & 2.2 & 0 & 0 & 0 & 0 & 0 & 25.5 \\
\hline & Stem & 7.3 & 15.2 & 0 & 0 & 0 & 0 & 0 & 0 & 0 & 22.5 \\
\hline & Leaf & 0 & 0 & 0 & 13.4 & 12.4 & 0 & 0 & 0 & 0 & 25.8 \\
\hline \multirow{2}{*}{$\begin{array}{l}\text { S. } \\
\text { didymobot } \\
\text { rya }\end{array}$} & Flower & 78.8 & 5.4 & 2.5 & 14.8 & 110.8 & 7.3 & 0 & 0 & 0 & 219.6 \\
\hline & Leaf & 2.4 & 10.5 & I.I & 0 & 38.9 & 0 & 0 & 0 & 0.9 & 53.8 \\
\hline \multirow{2}{*}{$\begin{array}{l}P . \\
\text { hysteroph } \\
\text { orus }\end{array}$} & Flower & 0 & 0 & 0 & 0 & 0 & 0 & 0 & 0 & 0 & 0 \\
\hline & Leaf & 0 & 0 & 1.2 & 0 & 0 & 0.8 & 0 & 0 & 0 & 2 \\
\hline \multirow[t]{2}{*}{ T. stans } & Flower & 58.5 & 161.7 & 0.3 & 3.9 & 263.3 & 0 & 3.95 & 14.5 & 0 & 506.2 \\
\hline & Leaf & 2.0 & 0 & 0 & 0 & 0 & 0 & 0 & 0 & 0 & 2.0 \\
\hline$r$ & & 0.94 & 0.88 & 0.02 & 0.75 & 0.84 & -0.06 & 0.65 & 0.65 & NA & 1 \\
\hline Probabilit & & $0.004^{*}$ & $0.02 *$ & 0.95 & 0.08 & $0.03 *$ & 0.89 & 0.15 & 0.15 & NA & $<0.001 *$ \\
\hline y & & & & & & & & & & & \\
\hline
\end{tabular}

$r$ is Spearman coefficient of correlation between median survival time of mosquitoes and sugars in preferred parts of plants $* \mathrm{P} \leq 0.05$ (significant association of sugar with median survival time). NA is non applicable

between each of the three types of sugars (glucose, fructose, and gulose) and mosquito survival (Table 6).

For mosquito fecundity, there was a positive, but not significant, correlation between the total sugar concentration in preferred feeding parts of plants and numbers of eggs laid when mosquitoes were offered one blood meal $(\mathrm{r}=$ $0.65, \mathrm{P}=0.15)$. The same result was obtained when mosquitoes were offered three blood meals $(r=0.14, P=$ $0.78)$. Nevertheless, the coefficient of correlation was clearly higher with one blood meal. There was a significant correlation between the proportion of mosquitoes ovipositing and sugar concentrations in plants $(\mathrm{r}=1.00, \mathrm{P}$ $<0.001)$.

\section{Discussion}

In a previous study, An. gambiae in western Kenya was demonstrated to have a preference ranking for feeding on different plants and plant parts [16]. The objective of the present study was to take a subset of these plants and determine whether data on the mosquito's survival and fecundity form a ranking that corresponds to the previously determined feeding-preference ranking.

With the exception of mosquitoes exposed to P. hysterophorus, the ranking of the survival and of the fecundity of mosquitoes following exposure to plants was remarkably similar to the previously established feeding preferences.
These values were also consistent with total sugar concentration and with the concentrations of three individual sugars (glucose, fructose and gulose) in the sites on these plants at which the mosquitoes especially often fed (flowers for T. stans, S. didymobotrya and H. patens, stems for $R$. communis, and leaves for L. camara and P. hysterophorus) [16]. These findings suggest that the sugar content in the different plant parts is approximately proportional to the amount of sugar available to the mosquitoes. Because a substantial proportion of a mosquito's energy reserves come from the sugar it consumes [22], variation among plant species in sugar content may potentially affect mosquito fitness. This study has shown that the choice of sugar source may be determined to a large extent by plant attributes including the particular types of sugar present and their concentration.

Besides fructose, glucose, mannose, sucrose, raffinose and galactose, gulose and allose were also detected, two sugars that have not been reported in previous analyses of nectar [23-25]. In the previous study [16], these sugars were also detected in the guts of An. gambiae, suggesting that these monosaccharides may occur in floral and other plant tissue. Detailed observations on the feeding behaviour of the mosquito and analyses of the plant parts fed upon may provide further insight into the general properties underlying the preference process and the related fitness gain. 
Lantana camara is a special case. Despite the flowers of this plant being rich in sugar and the leaves being poor in sugar, An. gambiae fed mainly on L. camara's leaves [16]. An explanation for this may be related to the long corollas of $L$. camara's flowers, perhaps making the nectar in the flowers of this plant species inaccessible to mosquitoes, forcing An. gambiae to feed on the less nutritious leaves. This in turn might help to explain L. camara's low position in An. gambiae's feeding-preference ranking observed in the previous study [16], as well as its poor performance on this plant species, as reported also by other previous studies $[14,15]$.

In view of An. gambiae's high preference-ranking for $P$. hysterophorus [16], this plant species is another special case, as the findings of this study go against what was expected. In the earlier study, the mosquitoes were seen frequently applying the tip of the proboscis to this plant's parts [16], but the poor survival and fecundity of mosquitoes on this plant species calls towards reconsidering interpreting this behaviour as instances of the mosquito feeding on plantderived sugar. The flowers of $P$. hysterophorus had no detectable monosaccharides and only a low level of the disaccharide sucrose was found in the leaves of this plant. The mosquito's performance (survival on the plant and fecundity following one blood meal) on $P$. hysterophorus was comparable to its performance on the negative control. On the whole, the findings from the previous study [16] combined with those from the present study suggest a hypothesis currently being investigated: that with $P$. hysterophorus, there are plant constituents other than sugars that may be beneficial to the mosquito in hitherto unrecognized ways.

In the experiment where mosquitoes were offered three blood meals, there was no evidence of plant feeding affecting the number of eggs produced or oviposited by individual females. However, except for the P. hysterophorus group, the percentages of females that oviposited were significantly higher for the mosquitoes that had fed on the more preferred plants. This indicates that, although multiple blood meals can compensate for sugar $[9,26,27]$, initial access to sugar has an advantageous effect on the An. gambiae's fecundity even when repeated access to blood meals becomes possible.

On the whole, these findings suggest that the complexity and importance of mosquito-plant relationships are not as widely appreciated as they should be. For the mosquito, there appear to be distinct benefits when feeding on the floral and extrafloral nectar of different plant species. Variation in sugar content appears to be the primary factor accounting for fitness-related effects of different plant species on the mosquito's survival and fecundity. However, there is also evidence that, with some plants, An. gambiae may also frequently ingest plant-origin material from leaves [16] and perhaps from plant parts other than floral and extrafloral nectaries. Ingestion of plant-origin material other than nectar may be a general phenomenon in mosquitoes, as examinations of the midguts of Culex pipiens molestus, Anopheles sergentii, Anopheles claviger and Aedes caspius (Diptera: Culicidae) have revealed the presence of plant tissues $[28,29]$. This study underlines that access to sugar-rich plants can be indispensable to mosquito survival and fecundity, with the mosquitoes tending to get sugar from floral and extrafloral nectaries. However, there is now a reluctance to call all instances of a mosquito ingesting plant-origin material 'feeding' because the word 'feeding' implies something to do with nutrition and it is not clearly the case that obtaining nutrients is always relevant when plant-origin material is ingested. The results of the present study presented two examples of plant species from which An. gambiae ingested sugar primarily from the leaves [16], and the data from these two plant species resulted in two contrasting situations. In the case of $L$. camara, mosquitoes fed especially from the plant's leaves [16] where sugar content is low. Their poor performance on this plant is consistent with its low preference ranking in the earlier study [16]. Anopheles gambiae's strong preference for $P$. hysterophorus [16], despite poor performance on this plant, appears to be more paradoxical, and current studies underway may clarify the adaptive significance of An. gambiae's preference for this plant species.

\section{Authors' contributions}

HM participated in the design of the study, conducted all the experimental work, analysed and summarized the data and drafted the manuscript. LCG co-designed and coordinated the study, supervised the experimental work, analysis and summary of the data, and contributed to the manuscript. JIG, AH, JCB co-designed and co-ordinated the work, and contributed to the manuscript. WAF codesigned and contributed to the manuscript. RRJ contributed to the manuscript. All authors actively contributed to the interpretation of the findings, read and approved the final manuscript.

\section{Acknowledgements}

We thank Tom Guda, Edward Nyandat, James Kongere, Silas Otieno, Samuel Orao, Jackton Arija, Michael Ogallo, Lawrence Omukuba and James Wauna for technical assistance. For providing logistic support, we extend many thanks to other ICIPE-Mbita staff. We thank Daniel Impoinvil for his comments on an early draft of this manuscript. This study was based, in part, on U.S. National Institutes of Health (NIH) grant R2I-AI062957 and was supported by NIH grants IUI9 (AI) 455 I I, ID43TWOI I 43 and 5D43TW00920. RRJ was supported by grants from the Royal Society of New Zealand (Marsden Fund and James Coop fellowship). H. M. was supported by the International Centre of Insect Physiology and Ecology (ICIPE) and by the African Regional Post-graduate Programme in Insect Science (ARPPIS) training fellowship. 


\section{References}

I. Yuval B: The other habit: sugar feeding by mosquitoes. Bull Soc Vector Ecol 1992, I 7:150-156.

2. Foster WA: Mosquito sugar feeding and reproductive energetics. Ann Rev Entomol 1995, 40:443-474.

3. White GB: Anopheles gambiae complex and disease transmission in Africa. Trans R Soc Trop Med Hyg 1974, 68:278-30I.

4. Service MW: A guide to medical entomology The Macmillan Press; 1980:44.

5. Collins FH, Paskewitz SM: Malaria: current and future prospects for control. Ann Rev Entomol 1995, 40:195-219.

6. Nayar JK, Van Handel E: The fuel for sustained mosquito flight. J Insect Physiol 197I, I 7:47I-48I.

7. Nayar JK, Sauerman DM: Physiological effects of carbohydrates on survival, metabolism, and flight potential of female Aedes taeniorhynchus. J Insect Physiol 1971, I 7:2221-2233.

8. Straif SC, Beier JC: Effects of sugar availability on the blood feeding behavior of Anopheles gambiae (Diptera: Culicidae). J Med Entomol 1996, 33:608-6I2.

9. Gary RE Jr, Foster WA: Effects of available sugar on the reproductive fitness and vectorial capacity of the malaria vector Anopheles gambiae (Diptera: Culicidae). J Med Entomol 200I, 38:22-28.

10. Okech BA, Gouagna LC, Knols BG], Killeen GF, Kabiru EW, Beier JC, Yan G, Githure Jl: Influence of sugar availability and indoor microclimate on survival of Anopheles gambiae (Diptera: Culicidae) under semifield conditions in Western Kenya. J Med Entomol 2003, 40:657-663.

II. Okech BA, Gouagna LC, Knols BGJ, Kabiru EW, Killeen GF, Beier JC, Yan G, Githure Jl: Influence of indoor microclimate and diet on survival of Anopheles gambiae s.s. (Diptera: Culicidae) in village house conditions in western Kenya. Int J Trop Insect Science 2004, 24:207-2I 2 .

12. Klowden MJ, Dutro SM: Effects of carbohydrate ingestion on the pre-oviposition behavior of the mosquito Aedes aegypti (L.). Bull Soc Vector Ecol 1990, 15:59-62.

13. Loubinos LP, Conn J: Fecundity, parity, and adult feeding relationships among Nyssorhynchus malaria vectors from Venezuela. Mem Inst Oswaldo Cruz 1991, 86:57-66.

14. Gary RE Jr, Foster WA: Anopheles gambiae feeding and survival on honeydew and extra-floral nectar of peridomestic plants. Med Vet Entomol 2004, I 8:102-107.

15. Impoinvil DE, Kongere JO, Foster WA, Njiru BN, Killeen GF, Githure JI, Beier JC, Hassanali A, Knols BGJ: Feeding and survival of the malaria vector Anopheles gambiae on plants growing in Kenya. Med Vet Entomol 2004, I 8: I08-II5.

16. Manda H, Gouagna LC, Nyandat E, Kabiru EW, Jackson RR, Foster WA, Githure JI, Beier JC, Hassanali A: Discriminative feeding behaviour of Anopheles gambiae s.s. on endemic plants in western Kenya. Med Vet Entomol 2007, 2 I : I03-I I I.

17. Mutero CM, Ouma JH, Agak BK, Wanderi JA, Copeland RS: Malaria prevalence and use of self-protection measures against mosquitoes in Suba District, Kenya. East African Med J 1998, 75: $11-16$.

18. Minakawa N, Mutero CM, Githure JI, Beier JC, Yan G: Spatial distribution and habitat characterization of anopheline mosquito larvae in western Kenya. Am J Trop Med Hyg 1999, 61:1010-1016.

19. Gouagna LC, Ferguson HM, Okech BA, Killeen GF, Kabiru EW, Beier JC, Githure JI, Yan G: Plasmodium falciparum malaria disease manifestations in humans and transmission to Anopheles gambiae: a field study in western Kenya. Parasitol 2004, I 28:235-243.

20. Briegel $\mathrm{H}$, Hörler $\mathrm{E}$ : Multiple blood meals as a reproductive strategy in Anopheles (Diptera: Culicidae). J Med Entomol 1993, 30:975-985.

21. Hamilton JGC, El Naiem DA: Sugars in the gut of the sandfly Phlebotomus orientalis from Dinder National Park, Eastern Sudan. Med Vet Entomol 2000, 14:64-70.

22. Shahid AA, Parveen T, Reisen WK: Changes in weight, calories and triglyceride content of sucrose fed Culex tritaeniorhynchus Giles and Anopheles stephensi Liston. Pakistan J Zool 1980, 12:163-169.

23. Baker HG, Baker I: Chemical constituents of nectar in relation to pollination mechanisms and phylogeny. In Biochemical aspects of evolutionary biology Edited by: Nitecki MH. Chicago University Press; 1981:131-171.
24. Koptur S: Extrafloral nectar-mediated interactions between insects and plants. In Insect-plant interactions Volume 4. Edited by: Bernays EA. CRC Press; 1992:81-129.

25. Lotz CN, Schondube JE: Sugar preferences in nectar- and fruiteating birds: behavioral patterns and physiological causes. Biotropica 2006, 38:3-15.

26. Scott TW, Naksathit A, Day JF, Kittayapong P, Edman JD: A fitness advantage for Aedes aegypti and viruses it transmits when females feed only on human blood. Am J Trop Med Hyg 1997, 57:235-239.

27. Costero A, Edman JD, Clark GG, Scott TW: Life-table study of Aedes aegypti (Diptera: Culicidae) in Puerto Rico fed only human blood versus blood plus sugar. J Med Entomol 1998, 35:809-8I3.

28. Schlein Y, Müller G: Assessment of plant tissue by sand flies (Diptera: Psychodidae) and Mosquitoes (Diptera: Culicidae). J Med Entomol 1995, 32:882-887.

29. Müller $G$, Schlein $Y$ : The frugal diet of mosquitoes in adverse conditions. Med Vet Entomol 2005, 19:413-422.
Publish with Bio Med Central and every scientist can read your work free of charge

"BioMed Central will be the most significant development for disseminating the results of biomedical research in our lifetime. "

Sir Paul Nurse, Cancer Research UK

Your research papers will be:

- available free of charge to the entire biomedical community

- peer reviewed and published immediately upon acceptance

- cited in PubMed and archived on PubMed Central

- yours - you keep the copyright

Submit your manuscript here:

http://www.biomedcentral.com/info/publishing_adv.asp
BiolMedcentral 